\title{
Urban expansion and change of land uses: city of Mexicali 1990-2005
}

\author{
O. Leyva-Camacho ${ }^{1}$, R. Venegas-Cardoso ${ }^{2}$, R. Rojas-Caldelas ${ }^{2}$, \\ A. Ranfla-González ${ }^{1}$ \& C. Pena-Salmon ${ }^{2}$ \\ ${ }^{I}$ Social Sciences Research Institute, \\ University Autonomous of Baja California, Mexico \\ ${ }^{2}$ Faculty of Architecture, University Autonomous of Baja California, \\ Mexico
}

\begin{abstract}
Mexicali has an important economic role within the state of Baja California, Mexico, and its urban economic dynamic has been a central piece of regional development in the Mexicali valley. This has produced a rapid urbanization of the rural-urban interface, which has intensified energy, material and population exchanges between the central city and its hinterlands. Such a dynamic has produced urban sprawl and a fast restructuring of the urban regional spatial development. Thus, the purpose of this paper is to analyze the spatial dynamics of the rural-urban interface of Mexicali, from 1990-2005. Urban spatial expansion was analyzed by satellite images, LANDSAT TM5 and LANDSAT ETM7 taken in the dry season, to identify land use changes and the physical expansion of the urban area over the last 15 years. Results have showed that Mexicali's urban area has expanded by around $32 \mathrm{~km}^{2}$, which means an increase of $34 \%$ during this period. Meanwhile small cities located in the hinterlands have experienced lower rates of population growth and physical expansion. Some small cities have been absorbed and others have developed over urban corridors to the central city. Changes in spatial patterns of urban structure have been accompanied by the evolution of urban functions and special interactions between the central city and its hinterlands. Lastly, the urbanization process is still in progress, but there are also evidences of urban sprawl in the hinterlands. Keywords: urban expansion, urbanization, land cover change, rural-urban interface.
\end{abstract}




\section{Introduction}

In the sphere of the developed and developing world the central concerns of planners are to manage the expansion of urban areas into the countryside to prevent negative impacts, such as the degradation of natural ecosystems, loss of productive agricultural land and reduction of landscape amenity. Mexicali has not escaped the effects of urban sprawl. While numerous territorial strategies and plans make an effort to guide development in the rural-urban interface of Mexicali, their success has generally been limited.

The path of the demographic concentration is an important economic and social characteristic of an urban region. There is a great amount of available data to study the subject. In the research for literature in urban geography, it is clear that most of the researching has focused on urbanization analysis and urban systems. However, there are a few studies about inner space structure, and the existing ones talked mainly about paths of industrial location and land uses. The aim of this study is to explore the population and spatial dynamics of the ruralurban interface of Mexicali, from 1990-2005. The paper begins by a brief review of theory and methodological concepts that lead the investigation, and then turns to the case study of Mexicali.

\section{Urban expansion of Mexicali}

\subsection{Description of the area of study}

Mexico is a country that has observed and accelerated urbanization processes, with implications of territorial concentration of economy and population. This process has generated regional imbalances that show a duality of few dynamic regions, and many regions slow and static. In this context, the regional economic development of the North border of Mexico, has promoted a system of cities that presents a tertiary and services profile, due to the access to commercial and cultural north-Americans products [1].

The city of Mexicali founded officially on March 14 of 1902, once the irrigation system was settled for Mexicali and Imperial Valley, Calexico, California was founded too.

The city of Mexicali has increased a process of development that has generated important changes in its social, economic, and environmental structure. Initially, the development of the city is due to agriculture development in Mexicali valley followed by the enlargement of the cultivable surface, migratory attraction and the establishment of the local industry. Later, with the breaking of the agricultural path at beginning of the industry cross-border plant, the consolidation of the tertiary and industry sector took place [2].

The important participation of Mexicali in the economic development of the state and its functional region, promotes the accelerated increase of local and regional population, due to its integration to the state urban system, such as capital of the organization and city of regional services [3]. 
The process of urban expansion, produced by the context mentioned above, originated an increase of colonies and industry activity not planned in the urban development, causing a mixture of incompatible urban uses that create a great variety of potential risks and conflicting situations for the resident population and urban infrastructures in the city.

In 2005, statistics shows that urban area of Mexicali city was 13,955.5 hectares, in which distributes a population of 653,046 inhabitants, the average population density was 46,75 inhabitants by hectare, and there was an occupation of 3.681 people by house [4].

The period from 1990 to 2005 showed a gradual growth dynamics (see figure 1) in population volume, house, and urban surface, which are followed by the population density, whereas the number of inhabitants by house falls down in inner urban area.

The population dynamic increases in inner urban area of Mexicali city; this reveals a change in population dynamics with a tendency of constant growing, with respect to the incorporation rate of new houses and urban land. It observed that houses and the new urban land maintain a dynamics that shows a deceleration in the intermediate period, in the third period observed a recover.

This urban expansion dynamics of Mexicali city, has confirmed three important growing zones located in the periphery.

The first zone is located at southeast, known as Nuevo Mexicali, where social interest housing, service, and commercial centers, industrial parks predominate, due to its proximity with the new cross border. The second zone, at south of Union road, located near to Mexico and Xochimilco lagoons has progressive popular, and interest social homes with limitations in the basic urban infrastructure and few commercial services.

In addition, the third zone, located at west, oriented to the development of progressive popular and social interest neighborhoods and industrial parks. Just, as the previous zone mentioned there are some limitations in infrastructure, commerce, and services.

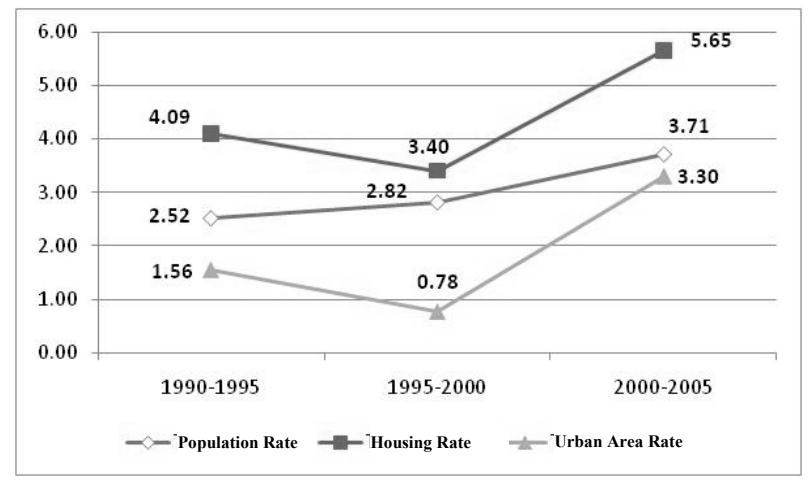

Figure 1: $\quad$ Growth rates in the city of Mexicali 1990-2005. 


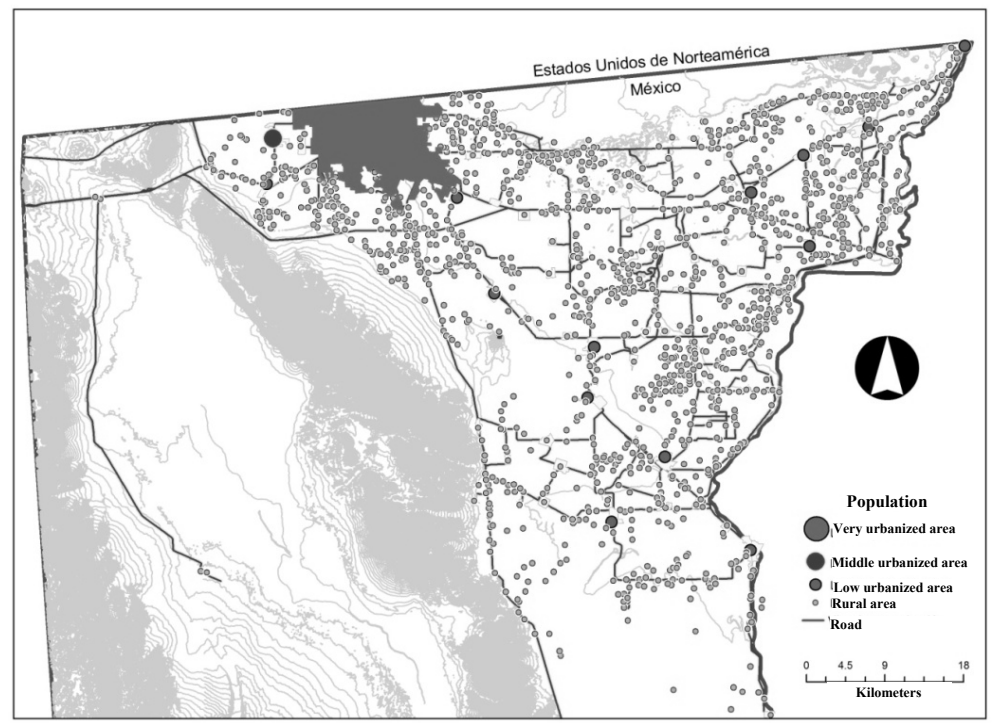

Figure 2: $\quad$ Regional urban system of the city of Mexicali 2005.

In the regional context, the urban dynamics of Mexicali city shows a group of localities linked to the city, in which dominates a distribution of the population that comes from rural dispersion to urban concentration, and the center of the economic activity comes from primary sector to secondary, and service sector [5].

In 2005, the region of the urban area of Mexicali city consisted of 1,471 localities; one locality of average urbanization (colony Santa Isabel), 14 localities with low urbanization, and 1.456 rural localities.

The functionality that Mexicali city maintains with the rest of localities maybe compared to a central city like in big western cities.

\subsection{Urbanization process analysis}

The human being tends to crowd together in a delimited habitat, which occupies less than $5 \%$ of the planet [6]. In these settlements, is where the majority of the population lives and works. They define urbanization and industrialization dynamics. This processes alter the natural environment that surrounds the settlements due to construction of residential areas and urban infrastructures [7].

For Paül and Tonts [8], the differences in patterns and processes of urban growth in various countries and regions are considered variations in culture, planning systems, levels of economic development and, the biophysical environment all have the potential to influence the nature of urban sprawl. Notwithstanding, there are some generalizations that can be made about urban sprawl: 
- An outward extension of new development.

- Low-density residential developments in new areas some distance from the central city.

- Leapfrog or scattered development, which is a type of discontinuous development.

- Transport networks dominated by private automobiles.

- Strip commercial development where urban activity corridors are mainly accessible by automobile and there is virtually no mixture of land uses.

Throughout much of the developed world, increasing levels of private car ownership have contributed strongly to urban sprawl as it has enabled individuals to settle considerable distances from places of employment and service provision.

To observe these characteristics, the city like a region is an approach used in regional planning that implies the physical management of the city, but the entire natural region, where the urban activity is located. It is a geographic area functionally correlated that a Central Urban Area includes (CUA), and his "hinterland" or Functional Urban Area (FUA) composed of smaller urban centers and rural areas, that are social and economically interdependent [9].

Therefore, surroundings from structuring of the city and its area of influence are identified and limited by analysis of the dynamics of population and use concentration, which reinforce themselves mutually in a Central Urban Area (CUA), during the sprawl process, the change favors to settlements that integrate the functional sub-regions [10].

It is important to emphasize that, the negative externalities of CUA, are caused by 1) the progress of localities around the city, 2) the population and employment concentration, and 3) the increase of mobility of population to the interior of the region.

In space terms, this dynamic conformed diverse land uses, such as residential, commercial, industrial, services, among others, it shows characteristic proportions from typical coverage, that vary according to geography, climate, land availability, social and economic distribution of population, while proportions of constructed surfaces and vegetation vary according to the intensity of the socioeconomic dynamics of these zones.

The disorderly aspect that observed in the rural-urban interface and the suburban development, are the two characteristics more visible of the urban change, which is associated to the structural change of the urban zones, this involves the processes of continuous reconstruction and infrastructure replacement and buildings [11].

Therefore, the specific distribution of population and the infrastructure, the way in which informally or formal the territory is occupied, and the particular configuration that the urban structure adopts generate the advantages of the city and the localities to attract and generate productive investment, as well as, the maintenance of the cohesion and regional social welfare. 


\subsection{Change in the land cover and land uses}

The physical trends derived from the space distribution of urban zones produce what in the remote sensing known as space and spectral signatures. According to the scale, there are two types of satellite image resolutions that are used to observe the urbanization dynamics [12].

With hi-resolution images with pixels size from 0.5 to 1.0 meter, these images allow to observe important components of the urban landscape (ways, buildings, bridges, trees, gardens, among others), and helps to develop land use and cover maps of sites and urban areas. The low- resolution satellite images, than vary between the 5 to 30 meters, it is possible, with them, to draw up a large classes of land cover and to translate the land use, through the combination of space and spectral differentiation between diverse categories of land cover, urban characteristics are identified, although the detail level is generalized.

The combination of Remote sensing and GIS including the aerial photography, offers an endless number of advantages, such as the rapidity and minor processing cost, the facility to compare temporary series, and to overcome the problems from access to the site. Nevertheless, within the disadvantages, they are included, low levels of resolution, limitation of the algorithms in the classification of land use, great variety of spectral signatures of the land under diverse conditions, an imperfect association between the use and the cover of the land, and the necessity of sophisticate equipment to realize these analyzes.

In the recent development and uses of models for the analysis of the change in the cover and land use, an endless number of conceptual and methodological advanced procedures in statistic, econometrics, and computer development have taken up; all these have improved the explanation capacity of nonlinear relations and correlations, the space dependency and its temporary dynamics.

Always, these empirical models will be limited, their capacities to explain and predict fluctuate according to the specific amount and quality of the data, the contexts where they are defined and calibrated. Though, its utility allows to identify correlations and the causality within a conceptual frame, which allow to preview scenes in situations near the real operation and according to the empirical situation of study [13].

\section{Methodology}

In this investigation, we analyze in local and regional scale the space distribution of population dynamics in Mexicali. First, to analyze the central urban area with population densities and defined tendency, we used urban Basic Geo-Statistic Area (AGEB in Spanish) for the years 1990 and 2005. To analyze the functional region, we use the data of Mexicali localities, location of population concentration in the regional urban system from the period 1990 to 2005 . Finally, estimate the space dynamics of the land cover of the urban region of Mexicali for years 1990 and 2005 through satellite images. 


\subsection{Analysis of the CUA}

GIS technology (ArcGis 9.3) is used to calculate and classify urban population density, then those with a defined tendency of urban structure, CUA, and spatial concentration densities are observed. The basic unit of information used in this study is the urban AGEBs for the years 1990 and 2005. In general, methodology consists of two parts; a) to calculate the Concentration of the Resident Population Index (crpi), taking as space reference the AGEB in its urban modality, applying the equation of the concentration index which is,

$$
c r p i=\frac{\rho p o_{i}}{\rho p o_{t}}
$$

where:

$\rho p o_{i}$ is the gross density of the resident population in an AGEB and, $\rho p o_{t}$ is the gross density of resident population in the total space of urban AGEB.

Subsequently, to observe the concentration of the population in the CUA, we use the distribution of population densities to create the relative frequency histogram and the accumulated frequencies curve.

\subsection{Analysis of the FUA}

For the case of localities, total population, specific data and, key data are listed geographically. Mexicali CUA demographic process and its urban regional system are classified according to INEGI methodology [14], as follows: a) very urbanized areas, (localities with 100,000 inhabitants or more and/or Capitals of State), b) middle urbanized areas (localities with population between 15,000 and 99,999 inhabitants), c) low urbanized areas (localities between 2,500 and 14,999 inhabitants), and d) rural areas (joint of localities with population below the 2,500 inhabitants).

We ranked population data of localities to distinguish their category as settlement, later we calculated localities' distance, in kilometers, with respect to the CUA center. In literature, the central area of reference, is determined by the location of central financial districts, or by the urban center, where central offices of government are located [10].

For this study, we considered central area as reference. The Mexicali government center is located at coordinates 643,158,425 meters longitude East and 3,612,867,353 meters latitude north. Once, we defined the center of city, the distances are moderate in lines between the center of city and the centers of localities. We generated concentration ranks in function of CUA, observed regional concentration of population in a scatter plot graphic, and graphed the tendency of function.

Finally, we selected the code of localities from 1990, 1995, 2000 and 2005, calculated the arithmetic growth, for 1990-2005 period, this exercise allows to observe by a scatter plot graph, based on the distance, the process of growth or decline of the population in localities. 


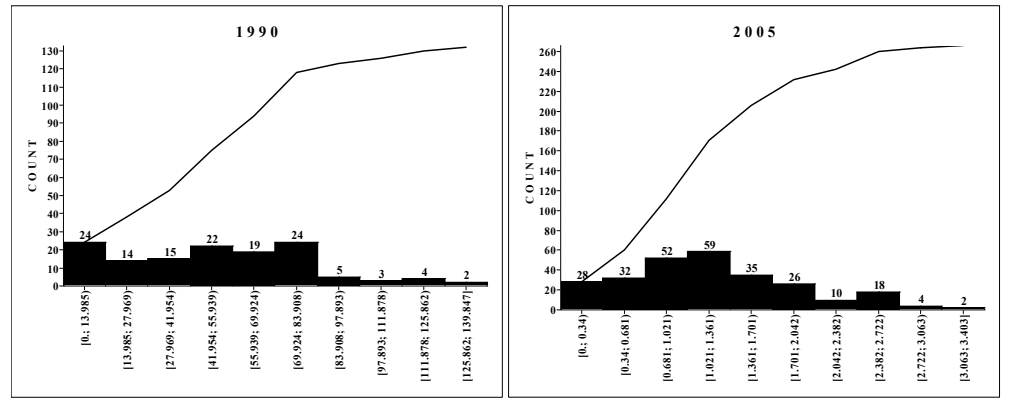

Figure 3: $\quad$ Population density of the CUA in 1990 and 2005.

\subsection{Land cover change analysis}

In order to observe the change of the land cover, from 1990 to 2005 in Mexicali, we used satellite images LANDSAT TM5 and ETM7 of the urban area and the contiguous crop growing area, and its composition in false color 7, 4, 1, to separate the categories of land uses, on basis of training sites. Subsequently, we classified with supervision, and $90 \%$ global precision, to apply the land change modeler.

We corrected 1990 and 2005 images with digital cartography from INEGI 1999 from the system of terrestrial roads and polygons from localities to scale 1:50,000 using the System of projection UTM WGS1984 for Zone 11 North.

In order to observe the urbanization dynamics, we divided the study area in 4 regions: Laguna Salada, Sierra de Cucapah, Mexicali City, Mexicali valley, and Mesa Arenosa. It is important to mention that, we worked only with the Mexicali valley area, in order to observe the dynamics of urban change through process of multivariate and generalization of Spatial Analysis ArcGIS 9.3 [15]. This is the area where the major interaction between county-city and the new urban spaces occurs in Mexicali region.

Finally, we use the IDRISI Land Change Modeller to analyze changes through the spatial analysis of areas (classes) that contributes to the land cover change, such as the persistence of dynamic of each land use.

\section{Results}

The dynamics of the resident population density shows a frequency histogram with an accumulation trend in the class intervals with the intermediate values. It shows a standard deviation, which corresponds to an urban structure more integrated in a more advanced phase of urban development.

At the beginning of analysis period, Mexicali's CUA shows a concentration of densities to the left, in the intervals with low and intermediate values of crpi, this situation indicates that there is less predominance in the central zone (see figure 1 at year 1990). Concentrations from the city, generated during 1995 to 2000 period distributed in a standard way. This distribution shows a slight standard deviation, which means that there is a trend to conform a small central zone. 
Finally, the 2005 period, observes a considerable surface of the city with a very elevated population concentration in the intervals of intermediate values, and crpi, with a defined standard deviation distribution. This graphic confirms the existence of a central zone, as it shows in the figure 1 at year 2005.

In the regional context, the urban expansion of the urban center is where most of the urbanization occurs. This location trend is provoked, in some way, by the industrial parks in the urban area. Mexicali city has a greater importance on demographic and economic aspects, comparing with other settlements in the municipality.

The requirement of new area for urban settlements follows the dynamics of housing sector.

This urbanization process observes a centralized concentric tendency; the greater urban expansion is located to the south of Mexicali city. Suburban areas make a conurbation with cooperative farming areas, these are do not increase in number, but increase its population and are absorbed by urban area of Mexicali city.

The very urbanized Area (that corresponds to the CUA in regional scale), has the greater level of urbanization and it is located in Mexicali city, in previous decades in this area has promoted the fast development of urban area, with a high level of socioeconomic and territorial integration. The recent tendencies of urban expansion show that medium residential and industrial sectors have occupied the vacant spaces within urban area.

The area of middle urbanization that appears from 2000 to 2005, created a small population conglomerate located at 8 kilometers of the CUA, due to commercial and industrial development in that sector.

The low urbanized area, conformed by small communities to low levels of urbanization and the agricultural area, are located between the 10 and 70 kilometers of distance from CUA center. They concentrate to the south of the city following the corridor formed by the routes of the train, the state road to San Felipe, and the inter-municipal system of roads of the Valley of Mexicali. The trend of urban concentration explained by accessibility to these communities, such as, regional and state services located in Mexicali city.

The rural area characterized by small settlements located besides of federal borders roads and state ways. Most of these areas are predominantly crop growing areas, and there is, in smaller scale, some recreational and tourist centers of low density. The growing pressure on these areas is attributable to real estate and industrial developers' speculation. This dynamic produces land uses and mixtures that not always are compatible with currently urban planning.

Composition of Mexicali city includes a very urbanized area, a recent locality of middle urbanization, 13 low urbanized localities, and several rural localities. All localities are under the predominance and administration of the CUA.

The changes in demographic trend from period 1990-2005 indicate the expansion dynamics of CUA and those localities around the CUA (see figure 4). From 1990, the population and the surface conformed by the AGEBs of the central city, have increased their volume, with the exception of some localities in the edge of central city. 
By definition, urban concentration initiates when population rate in the central city is higher than the registered in peripheral localities. In 1990, most of Mexicali city CUA increased, in other localities this increase was observed but in a slower way.

Therefore, the population dynamics of Mexicali city, which is located near to central city, decrease faster than remote areas. This phenomenon is due to the extension of the urbanized area of Mexicali city. This dynamics indicates the principles of urban concentration in Mexicali. The urban concentration of CUA is due to large industry areas, commerce, services, and transferring facilities from CUA to the outlying localities.

In the urban region of Mexicali city, the changes of land cover occur on territories with favorable physical conditions for housing and infrastructure development, which is negative for primary sector. This urban expansion

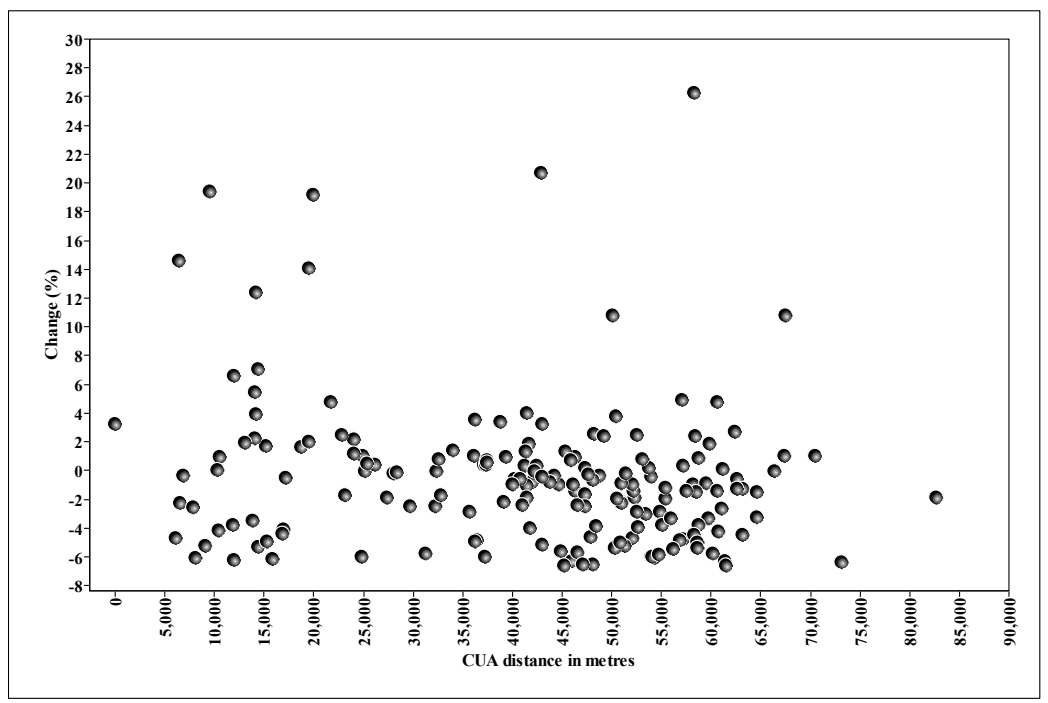

Figure 4: Growth of the localities of Mexicali FUA.

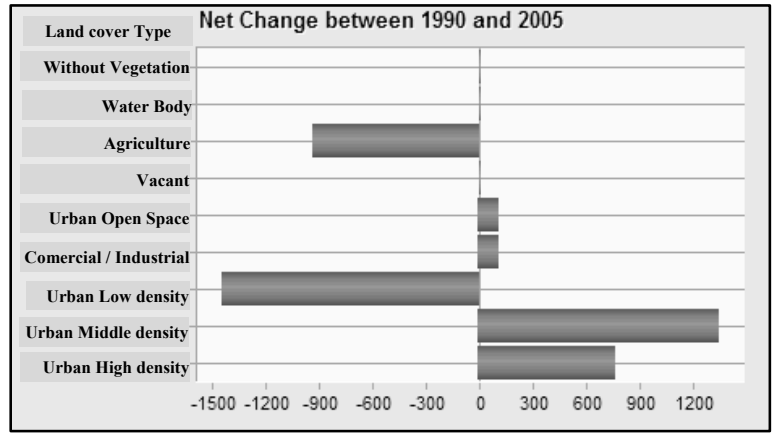

Figure 5: Global change by land covers categories in the period 1990-2005. 
expresses a process that alternates diffusion of the initial urban area (1990) and fusion of an urban landscape progressively saturated by 2005 .

The expansion persistence of high density in construction indicates (a priori) that the process of this class (high urban) follows a consolidated dynamics in the urban structure (as shows in the previous figure 5).

This can be verified by the census occurred in the period of analysis, that demonstrate an increase in the population density, which is associated to the accelerated processes of housing in the last 5 years.

In Mexicali city, the existing urban development policy that promotes urban expansion is generating a great pressure on the territorial reserves of the city, and tends to continue extending on agricultural area. The fact mentioned previously reduced the profitability in the primary sector. In addition, this urban expansion promotes the use of land in areas with telluric risk, and affects natural reservation areas where halophytes and other desert vegetation grow.

\section{Conclusions}

The reasons of urban concentration in the western cities are complex; these changes are attributed to transport improvements, the increase of the wealth and the local well-being, and to the fast urban expansion of CUAs.

In Mexicali city, the period from 1990 to 2005 shows a gradient of density and population concentration which trends to a distribution of bell of the densities, whereas the suburban and rural localities have lost population in several scales, localities in a moderate distance of the city center decrease quickly unlike the remote areas.

The concentration of population in CUA of Mexicali and outlaying localities, in both cases, is attributable to the fast urban expansion promoted by the border and state regional policies that stimulate one of the urban economies of fast escalation in the northwest of the country, dynamics that impulse the trajectory of polycentric urbanization.

The results show that distribution of construction densities are caused by accelerated urban expansion. This phenomenon occurred in areas with high and average urbanization. It shows a visible decrease on areas with low urbanization, which indicates a gradual absorption process of Mexicali outlying urban area and concentration of great part of the new urban residents. All this is the result of the present industrial intensification of Mexicali, and the real estate speculation promoted in the last years.

The urban shape for the 2005 presses and generates degradation of the near agricultural area, and represents a marginalization factor for population living in periphery, since public service centers and infrastructure are located in remote locations.

It is important to clarify that this methodology does not summarize the situation of Mexicali city, but it does show the growth of the city, and the trend of urban expansion. Thus, the evaluation proposed will consider a useful tool for urban planning. The modeling was created by adjusting structure and information of urbanization process in Mexicali. In this way, it is possible to 
conjugate the joint vision of the process with the possibility of future deeper analysis, if necessary, the extension of classes. Thus, the present methodology is a starting for future multiple analysis of this case.

\section{References}

[1] Herzog, L., Rethinking the U.S.-Mexico Border Environment, in The Shared Borderlands, H. Lawrence, Editor. 2000, Center for U.S.-Mexican Studies, University of California: San Diego.

[2] González, P., Crecimiento industrial y riesgo urbano: Caso de Mexicali, Baja California. Estudios Fronterizos, 1994(34): p. 9-30.

[3] CONAPO, Sistemas de ciudades y distribución espacial de la población en México. Vol. II. 1991, D.F.

[4] INEGI, II Conteo de Población y Vivienda 2005. Proyecto IRIS-SCINCE II Conteo de Población y Vivienda 2005. Baja California. 2005, Instituto Nacional de Estadística Geografía e Informática: México. p. 1 CD-ROM.

[5] Estrella, G. and A. Ranfla, Demografia y economía de una capital estatal. Estudios Fronterizos, 1996. 37(38): p. 9-32.

[6] Parr, J., Perspectives on the City-Region. Regional Studies, 2005. 39(5): p. 555-566.

[7] Anderson, P., P. Kanaroglou, and E. Miller, Urban form, energy and the enviroment: a review of issues, evidence and policy. Urban studies, 1996. 33(1): p. 7-35.

[8] Paül, V. and M. Tonts, Containing Urban Sprawl: Trends in Land Use and Spatial Planning in the Metropolitan Region of Barcelona. Journal of Environmental Planning and Management, 2005. 48(1): p. 7-35.

[9] Ravetz, J., City-region 2020 : integrated planning for a sustainable environment. 2000, London: Earthscan. 307.

[10] Wang, F. and Y. Zhou, Modelling urban popullation densities in Beijing 1982-90: Suburbanisation and its causes. Urban studies, 1999. 36(2): p. 271-287.

[11] Elvidge, C., et al., Urbanization, in Land Change Science: Observing, Monitoring and Understanding Trajectories of Change on the Earth's Surface, G. Gutman, et al., Editors. 2004, Kluwer Academic Publishers: Dordrecht, The Netherlands.

[12] Gao, J., Digital Analysis of Remotely Sensed Imagery. 2009, New York: The McGraw-Hill Companies, Inc.

[13] Brown, D., et al., Modeling Land-Use and Land-Cover Change, in Land Change Science: Observing, Monitoring and Understanding Trajectories of Change on the Earth's Surface, G. Gutman, et al., Editors. 2004, Kluwer Academic Publishers: Dordrecht, The Netherlands.

[14] INEGI, Encuesta Nacional de Empleo. 2000, Aguascalientes: Instituto Nacional de Estadística, Geografía e Informática.

[15] LeGates, R., Think globally, act regionally: GIS and data visualization for social science and public policy research. 2005, Redlands, Ca.: ESRI Press. pp 155-178. 